\title{
Heurística GRASP para o Problema de Alocação de Navios em Berços
}

\author{
Enio C. Romagnome* Márcia A. Gomes-Ruggiero \\ Instituto de Matemática, Estatística e Computação Científica, IMECC, UNICAMP, \\ 13083-859, Campinas, SP \\ E-mail:ra134499@ime.unicamp.br, marcia@ime.unicamp.br.
}

Antonio Carlos Moretti

Faculdade de Ciências Aplicadas, FCA, UNICAMP

88040-900, Limeira,SP

E-mail: antonio.moretti@fca.unicamp.br

\section{RESUMO}

O presente trabalho tem por objetivo, tratar o Problema de Alocação de Navios em Berços usando a metaheurística GRASP. Tal problema tem sido objeto de estudo de muitos pesquisadores nos últimos anos, como em [1], [2] e [4], tendo em vista o forte impacto do setor de transporte marítimo no comércio mundial.

O Problema de Alocação de Navios em Berços consiste em atribuir navios em determinados locais, denominados berços, decidindo o horário e em qual berço o navio deverá atracar. O problema foi aqui tratado como discreto, onde o porto é dividido em vários berços cujo atendimento é dado a um navio por vez, e dinâmico, isto é, são dados os horários de chegada de cada navio e estes só poderão ser atendidos a partir desses horários dados, mesmo que cheguem antes ao porto. Deve-se ainda, obedecer os horários de abertura e encerramento de cada berço, bem como o horário limite que cada navio tem para permanecer atracado no berço.

Além disso, como em [3] e [4], o problema foi formulado como um Problema de Roteamento de Veículos de Mútiplas Garagens com Janela de Tempo, onde os navios são vistos como veículos e os berços como garagens. Os autores, [3] e [4], propõem heurísticas para resolução de uma formulação relaxada, na qual as restrições relacionadas à janela de tempo são penalizadas e incluídas na funçãoobjetivo, resultando em uma formulação equivalente a um Problema de Roteamento de Veículos Sem Janela de Tempo.

Neste trabalho propomos uma heurística baseada no Greedy Randomized Adaptive Search Procedures, GRASP, [5], [6] para obter uma solução do Problema com sua formulação original, sem penalização. Dessa forma, apresentamos uma abordagem diferente das encontradas em [3] e [4].

O GRASP consiste de duas fases, a primeira, construtiva e a segunda de busca local. Para a primeira fase, foi elaborada uma estratégia para obtenção de uma solução viável para o problema original. A cada etapa, é construída uma lista de navios candidatos a serem alocados em um dos berços. A seleção de navios para compor a lista de candidatos é feita através de uma função de mérito, introduzida neste trabalho, que visa quantificar a urgência de atendimento de cada navio, ponderando tempo de atendimento e de espera, custo associado ao navio, horários de funcionamento dos berços e a janela de tempo de cada navio.

Obtido um conjunto de soluções viáveis, são então selecionadas as de menor custo e acionado um processo de intensificação, visando obter, a partir desta solução, um ótimo local.

A heurística para a fase construtiva foi já testada computacionalmente. Realizamos testes com 7 , 10, 20, 40, 60 navios para serem alocados em, respectivamente, 2, 3, 5, 8, 13 berços. Em todos os

${ }^{*}$ Aluno de Mestrado/CAPES 
testes obtivemos uma porcentagem alta de soluções viáveis com tempo médio de 0.1 segundo. A fase de intensificação está em elaboração.

Palavras-chave: Problema de Alocação de Navios em Berços, MetaHeurísticas, GRASP.

\section{Referências}

[1] J.F. Cordeau, G. Laporte, P. Legato and L. Moccia, Models and tabu search heuristics for the BerthAllocation Problem, Transportation Science, 39 (2005) 526-538.

[2] K.H. Kim and K.C. Moon, Berth scheduling by simulated annealing, Transportation Research, Part B 37 (2003) 541-560.

[3] A.T. Lopes, V.M.L. Schulz e G.R. Mauri, Grasp com path relinking para o Problema de Alocação de Berços, Revista Eletrônica Pesquisa Operacional para Desenvolvimento, 3 (2011) 218-229.

[4] R.M. de Oliveira, G.R. Mauri and L.A. N. Lorena, Clustering search for the Berth Allocation Problem, Expert Systems with Applications, 39 (2012) 5499-5505.

[5] T.A. Feo and M.G.C. Resende, Greedy randomized adaptive search procedures, Journal of Global Optimization, 6 (1995) 109-133.

[6] G. Zäpfel, R. Braune and M. Bogl, "Metaheuristic Search Concepts: A Tutorial with Applications to Production and Logistics”, Springer, Berlim, 2010. 